\title{
CORRIGENDUM
}

\section{Deletion analysis of Ad5 E1a transcriptional control region: impact on tumor-selective expression of E1a and E1b}

\section{F Hedjran, K Shantanu and R Tony}

Cancer Gene Therapy (2011) 18, 760; doi:10.1038/cgt.2011.61

Correction to: Cancer Gene Therapy (2011) 18, 717-723 doi: 10.1038/cgt.2011.41; published online 5 August 2011

The author list was published incorrectly online. The correct author list is F Hedjran, S Kumar and T Reid.
The full names of the people thanked in the Acknowledgments should have been listed as Shakeela Dad, Marta Sartor and Yoel Bogoch. 